\title{
Using 3D Printing Technology in Prototype Production to Control the Dimensi- ons of Complexly Shaped Products
}

Filip Šproch, Vladimíra Schindlerová, Ivana Šajdlerová

Faculty of Mechanical Engineering, VSB - Technical University of Ostrava, 17. listopadu 15/2172, 70800 Ostrava

- Poruba. Czech Republic. E-mail: filip.sproch@vsb.cz, vladimira.schindlerova@vsb.cz, ivana.sajdlerova@vsb.cz

Prototype production is a key element in the process of developing a new product. The prototype is important both being the initial materialization of ideas and intentions related to the way the product is going to be designed, and also for the subsequent assessment of the technological solution. One of the technologies used in prototype production today is $3 \mathrm{D}$ printing. One of its advantages is quick adaptation to more complexly shaped prototypes, which makes it possible to come up with products which would be hard or even impossible to make in the past. The increasing availability of $3 \mathrm{D}$ printing equipment is making it all the more widely used. This paper was written to demonstrate the principles of the production of auxiliary gauges, which are used to check the dimensions of a more complexly shaped prototype. The possibilities of using 3D printing technologies in the conditions of an engineering company are also discussed. The conclusion of this paper focuses on the possibilities of integration between modern and classic technologies in piece and custom production.

Keywords: 3D Printing, Prototype Production, Auxiliary Gauges

\section{Introduction}

In today's resource-constrained environment, market pressure for new products is growing dramatically due to increasing access to worldwide markets. On the other hand, competition is growing dramatically as well. That is why companies are trying to overtake their competitors, launching new products which the market is not yet saturated with and thus securing their position on the market. [1]

However, the process of manufacturing a new product is a long and demanding journey where at the beginning we do not know whether the product will be fully functional and suit the customer's wishes. The manufacturing process is a complex chain, consisting of a series of links which are interconnected and thus the chain cannot be continued unless the previous link is fully functional. It is therefore necessary to divide the process into individual steps and continuously monitor and control the individual sub-sections so that the non-functioning part does not get farther along in the process. In addition to market research, where the main focus to analyse the demand, i.e. whether or not the product will ever be attractive for customers, one of the most important steps in designing a new product is the construction of a prototype.

The term "prototype" is understood as at least one sample version of a machine, device, product, or program. Prototypes make it possible to test the functionality of a product being designed. It can be both an actual thing or a virtual version of it. Prototyping is an essential stage in the process of designing a new product, namely a checkpoint, a part of the design stage, before the product enters production. This testing helps manufacturers avoid mass producing items which are not (fully) functional. Speaking of mass or large-scale production, this step has a decisive effect on the success or failure of the entire project. Nowadays, consumers only demand good quality products, which must meet not only their expectations, but also user parameters and legislative demands.Prototypes are tested for all physical, technical and aesthetic properties that the final product should have. Tests are performed on real or software created virtual prototypes.

Using virtual reality for testing reduces the cost of researching and analysing the physical and technological properties of a product. Today, these advanced technologies make it possible to speed up most timeconsuming phases of the production process. Designers use virtual models instead of real prototypes and analyse them using different types of simulations, focusing on real-life conditions in which the product will have to operate. This process is supported by modern computer software. First, the designer creates a virtual model. The next phase is the preparation of a virtual simulation, the aim of which is to outline the real conditions of the object's use.

In addition to virtual prototyping, the production of real prototypes, where the actual object is produced in accordance with customer requirements and technical specifications. The prototype is a fully functional product that is manufactured according to technical specifications and customer requirements. The problem with prototypes is that there is no standardized 
production process and machines and tools may not be readily available, which makes it is a demanding technological process with high production costs. Without creating a real prototype, it is not possible to test the product and detect problems before mass production is started.

This paper describes the production of prototypes in a mechanical engineering company, using conventional sheet metal processing technology combined with modern 3D printing and modelling. The case study was carried out at LAKUM Group, which is an umbrella name for LAKUM-KTL, a.s., LAKUM-AP, a.s., LAKUM-GALMA, a.s. and Massag, a.s. located near Ostrava. This company combines advanced 3D printing and modelling technology with conventional processing technology to create unique prototypes for its customers. The company also deals with surface treatment, pressing and CNC metal processing.

\section{Literature review}

3D printing technology, referred to as Digital Manufacturing or Additive Manufacturing (AM) or Rapid Prototyping (RP) technology, is a modelling process that creates a reconstruction of a physical surface or object from a digital 3D model. This technology uses digital data. The data is processed using 3D graphics software (CAD) or other devices, such as a 3D scanner which can scan a physical object to create a virtual 3D model. The created 3D models of objects are further prepared using a postprocessor which is a software converter of data from CAD / CAM system into the data language of a particular 3D printing machine. The principle of $3 \mathrm{D}$ technology allows you to convert any virtual model to a physical model using $3 \mathrm{D}$ printing. $[2,3,4,5,6,7]$

3D printing technology is based on an additive process whereby material is gradually added to create a physical model, as opposed to conventional machine tools, where material is removed from a solid block until the desired shape remains. $[4,8,9]$

$3 \mathrm{D}$ printing technology is an emerging digitized production technology that makes it possible to produce objects with a complex shape geometry at low cost, and also allows quick design of a number of prototypes. That is why this technology represents one of the most promising and revolutionary production options today. This technology has gained worldwide recognition and has attracted a lot of attention in recent years. $[3,4,8]$

$3 \mathrm{D}$ printing technology is used primarily in industries such as agriculture, aviation, robotics, aerospace and automotive, but also in the health sector; in fields such as plastic surgery, orthopaedics and dentistry. [10]

Today, 3D printing technology is capable of producing fully functional components in a wide range of materials such as:
- Metals - metals are used in aviation, automotive industry or biomedicine because they have excellent properties and 3D printing allows for great precision and signifficantly lower weight of the manufactured parts. Aluminium, nickel, cobalt, stainless steel or titanium alloys are used. [2,9]

- Polymers - polymers are the most widely used material for 3D printing due to their availability and properties. Polymers such as PLA, ABS, PP, or PE are used. [2]

- Ceramics - ceramics are mainly used in dentistry, but in the future they will definitely find their place, together with concrete, as a practical material for the construction industry, due to its technological properties.[2]

- Composites - are used for their versatility, low weight and customizable properties. Examples of composite materials are carbon fibres reinforced with polymer composites and glass fibre reinforced polymer composites. [12]

- Smart materials - intelligent materials have the potential to change the geometry and shape of an object in response to external conditions. Examples are some shape memory alloys, such as nickel-titanium, which are used in biomedical implants for the application of microelectromechanical devices. [2]

\section{Advantages of $3 \mathrm{D}$ printing}

The advantage of $3 \mathrm{D}$ printing for the production process is that a wide range of materials can be used. This variety has helped promote applications in many manufacturing sectors. Future directions focus more on military applications, including on-site printing of spare parts. It also saves production time, shortens the time after which a product can be launched on the market, saves material and simplifies the workability of highly complex products. [13]

\section{Disadvantages of 3D printing}

The disadvantages are related to the environment, where printers consume large amounts of electricity and can also slow down the movement towards ending humanity's dependence on plastics. Another disadvantage is the legal problems that will have to beworked on, in order to protect the intellectual property of manufacturers. The last disadvantage is the initial investment in this technology, which is in the order of hundreds of thousands of crowns. [13] 


\section{Case study}

The case study was realized in a real company environment. The production of measuring templates
(Model Test 1, Model Test 2) was carried out on a specific 3D printer using the given filament and predetermined printing parameters, see Tab. 1.

Tab. 1 Print parameters [14]

\begin{tabular}{|c|c|c|c|}
\hline \multicolumn{2}{|c|}{ Printer } & \multicolumn{2}{|l|}{ Fillamentum } \\
\hline \multicolumn{2}{|c|}{ 3D Printer Ultimaker S5 } & \multicolumn{2}{|c|}{ Ultimaker Tought PLA (black) } \\
\hline Average print strings & $2.850[\mathrm{~mm}]$ & Type of material & PLA \\
\hline Print volume & $330 \times 240 \times 300[\mathrm{~mm}]$ & Diameter of the filament & $2.850[\mathrm{~mm}]$ \\
\hline Number of extruders & 2 & \multirow{2}{*}{$\begin{array}{l}\text { Recommended printing temperature } \\
\text { Recommended platen temperature }\end{array}$} & $210-220\left[{ }^{\circ} \mathrm{C}\right]$ \\
\hline Number of nozzles & 2 & & $60\left[{ }^{\circ} \mathrm{C}\right]$ \\
\hline Nozzle diameter, head & $\begin{array}{c}0.250 / 0.400 / 0.600 / \\
0.800[\mathrm{~mm}]\end{array}$ & Recommended platen temperature & \\
\hline $\begin{array}{l}\text { Working temperature of } \\
\text { the nozzle }\end{array}$ & $180-280\left[{ }^{\circ} \mathrm{C}\right]$ & \multirow[t]{4}{*}{ 1. 1} & \\
\hline Heating pad & $20-140\left[{ }^{\circ} \mathrm{C}\right]$ & & \\
\hline Rated power & $500 \mathrm{~W}$ & & \\
\hline Technology & FFF/FDM & & \\
\hline XYZ Resolution & $6.900 / 6.900 / 2.500[\mu \mathrm{m}]$ & \multirow{2}{*}{$\begin{array}{l}\text { CTE } \\
\text { parameters }\end{array}$} & $41 \times 10-6 \mathrm{~m} / \mathrm{m} \cdot \mathrm{K}]$ \\
\hline \multicolumn{3}{|c|}{ Print parameters } & \\
\hline & & Model Test 1 & Model Test 2 \\
\hline \multicolumn{2}{|l|}{ Print Speed } & $45\left[\mathrm{~m} \cdot \mathrm{s}^{-1}\right]$ & $45\left[\mathrm{~m} \cdot \mathrm{s}^{-1}\right]$ \\
\hline \multicolumn{2}{|l|}{ Travel Speed } & $150\left[\mathrm{~m} \cdot \mathrm{s}^{-1}\right]$ & $150\left[\mathrm{~m} \cdot \mathrm{s}^{-1}\right]$ \\
\hline \multicolumn{2}{|l|}{ Traver Jerk } & $30\left[\mathrm{~m} \cdot \mathrm{s}^{-1}\right]$ & $30\left[\mathrm{~m} \cdot \mathrm{s}^{-1}\right]$ \\
\hline \multicolumn{2}{|l|}{ Printing Temperature } & $210\left[{ }^{\circ} \mathrm{C}\right]$ & $210\left[{ }^{\circ} \mathrm{C}\right]$ \\
\hline \multicolumn{2}{|l|}{ Build Plate Temperature } & $60\left[{ }^{\circ} \mathrm{C}\right]$ & $60\left[{ }^{\circ} \mathrm{C}\right]$ \\
\hline \multicolumn{2}{|l|}{ Quality Layer Height } & $0.100[\mathrm{~mm}]$ & $0.100[\mathrm{~mm}]$ \\
\hline \multicolumn{2}{|l|}{ Printing Time } & 7.500 [hr.] & 44 [min.] \\
\hline \multicolumn{2}{|l|}{ Nozzle diameter, head } & $4[\mathrm{~mm}]$ & $4[\mathrm{~mm}]$ \\
\hline & & ftware & \\
\hline
\end{tabular}

The first part of the study describes the process of manufacturing a control template using 3D printing. The first step is to create a $3 \mathrm{D}$ virtual template in CAD software. In this particular case, Autodesk Inventor software was used, among other software used are SolidWorks, Pro / ENGINEER, Catia or Solid Edge.
The designer creates a 3D model of the template directly on the given product model $(\mathrm{B}, \mathrm{C})$, which he creates in case he sells the products, or he makes drawings and receives the 3D models from the customer (A). The model is created directly on the product to check the given dimension. Process of manufacturing, see in Fig. 1.

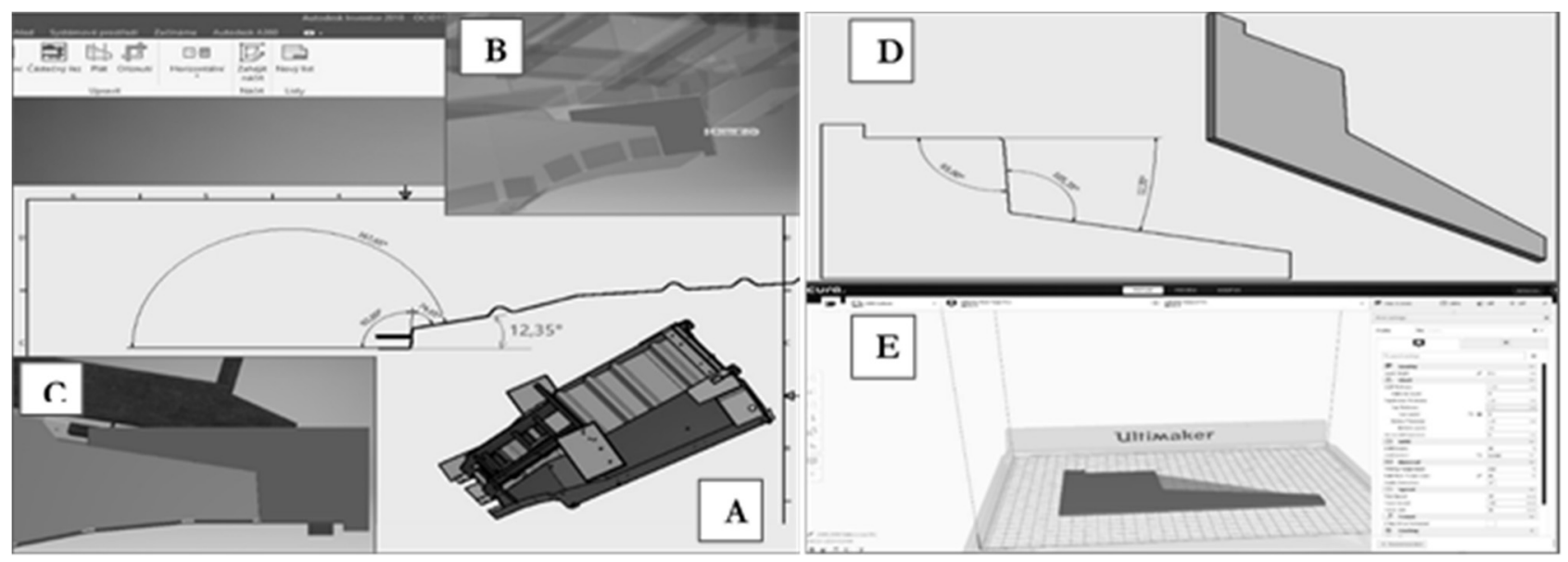

Fig. 1 Process of manufacturing 
After creating a 3D template model in the CAD software, the model is transferred to the $3 \mathrm{D}$ printing preparation software. In this case, the Ultimaker Cura software is used. Other platforms used are Simplify3D or PrusaSlicer. Here the given 3D printing parameters
(E) are set, subsequently the printing is set, which is then converted to the printer language using the postprocessor, and printing is launched. The printing parameters for the measurement templates are shown in Tab. 1. Process of 3D printing, see in Fig. 2.
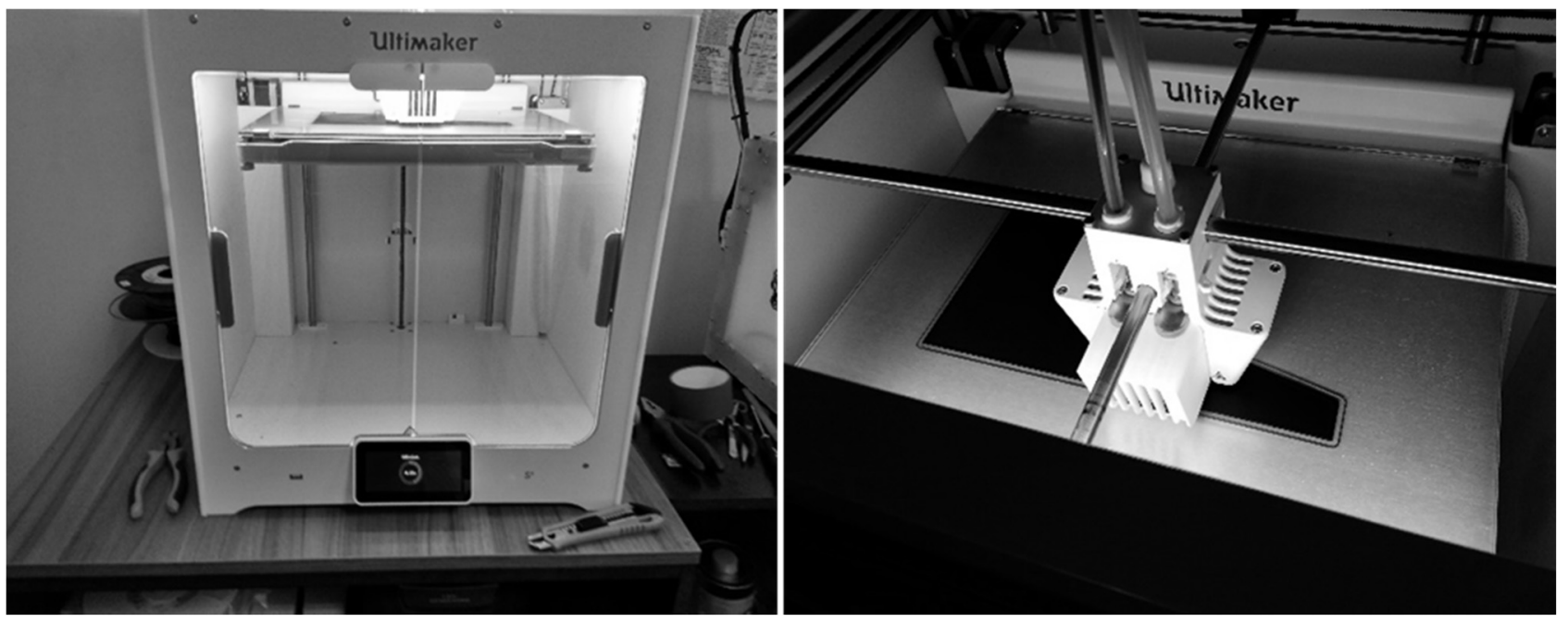

Fig. 2 Process of $3 D$ printing

The printed models (Figure 3) are handed over to the factory where they check the complexity of dimensions which are difficult to measure with conventional measuring means. The Test 1 model is a template for checking the correct size of the product angle, see in
Fig. 3. The Test 2 model is a gauge for checking the size of the radius, see in Fig. 3. Both models were checked on a $3 \mathrm{D}$ coordinate measuring instrument Zeiss.
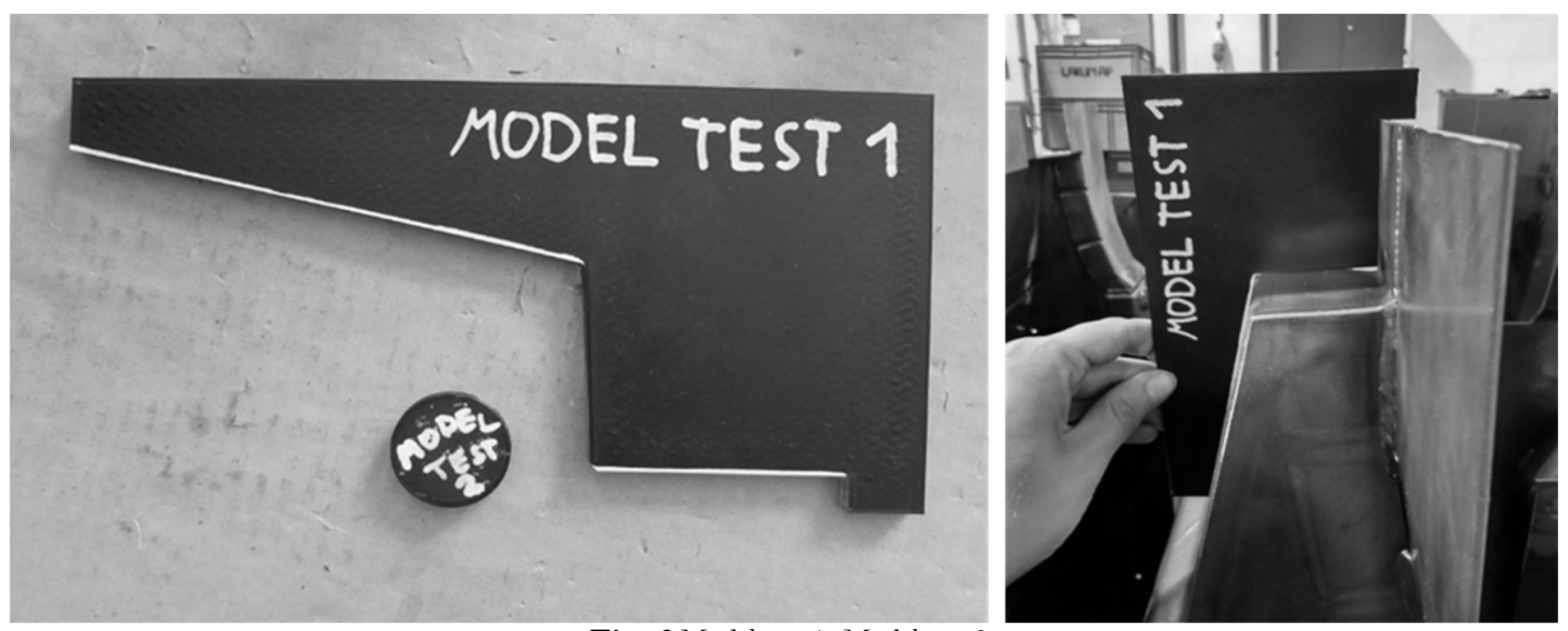

Fig. 3 Model test 1, Model test 2

The second part of the study evaluates the accuracy of $3 \mathrm{D}$ printing. Accuracy is evaluated based on the control measurements of the printed templates. The inspection was carried out using a $3 \mathrm{D}$ coordinate measuring device Zeiss DURAMAX, calibrated according to DIN EN ISO 10360. The measurement was carried out by the touch probe measurement method. For Model Test 1, the angle size was measured 10 times, and measurements were made comparing the variations in the distance between the points of the actual model and the virtual model. This measurement consists of 23 points that were distributed over the model area. From the measured points the deviation of the actual shape of the measured object from the ideal shape (virtual template) is determined. This measurement was performed 10 times. In the second Test 2 model, the pore size was checked 10 times and the circularity deviation was measured 10 times. The averages were calculated from the measured values. 


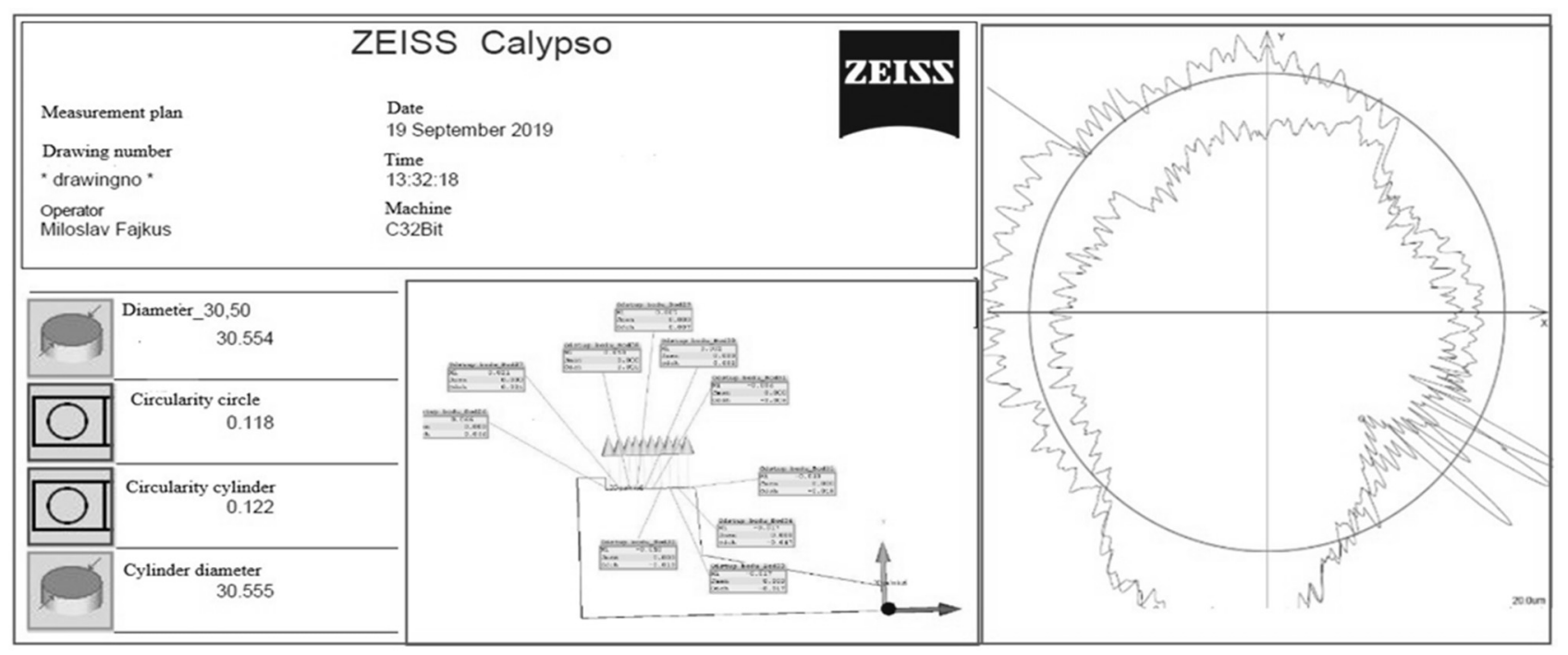

Fig. 4 Measurement using $3 D$ Zeiss system

Tab. 2 Measured values Model Test 1

Measurement results Model Test 1

\begin{tabular}{|c|c|c|c|c|c|c|c|c|c|c|}
\hline & \multicolumn{10}{|c|}{ Deviations of the actual shape of the measured template from the ideal template shape } \\
\hline Points & \multicolumn{10}{|c|}{ Measurement $1-10[\mathrm{~mm}]$} \\
\hline 1 & -0.014 & -0.017 & -0.018 & -0.016 & -0.018 & -0.017 & -0.018 & -0.017 & -0.015 & -0.016 \\
\hline 2 & 0.001 & -0.003 & -0.003 & -0.001 & -0.004 & -0.003 & -0.004 & -0.003 & -0.006 & -0.001 \\
\hline 3 & 0.016 & 0.011 & 0.010 & 0.014 & 0.010 & 0.011 & 0.009 & 0.011 & 0.012 & 0.009 \\
\hline 4 & 0.010 & 0.008 & 0.007 & 0.010 & 0.007 & 0.008 & 0.007 & 0.009 & 0.007 & 0.011 \\
\hline 5 & 0.009 & 0.006 & 0.005 & 0.009 & 0.005 & 0.007 & 0.005 & 0.006 & 0.005 & 0.005 \\
\hline 6 & 0.010 & 0.007 & 0.007 & 0.009 & 0.007 & 0.008 & 0.007 & 0.007 & 0.008 & 0.009 \\
\hline 7 & 0.004 & 0.001 & 0.001 & 0.004 & 0.001 & 0.002 & 0.001 & 0.001 & 0.001 & 0.003 \\
\hline 8 & 0.006 & 0.003 & 0.003 & 0.005 & 0.003 & 0.004 & 0.003 & 0.004 & 0.003 & 0.003 \\
\hline 9 & 0.004 & 0.001 & 0.001 & 0.006 & 0.001 & 0.002 & 0.001 & 0.002 & 0.003 & 0.002 \\
\hline 10 & 0.009 & 0.006 & 0.006 & 0.008 & 0.006 & 0.007 & 0.006 & 0.006 & 0.008 & 0.007 \\
\hline 11 & 0.017 & 0.017 & 0.016 & 0.009 & 0.016 & 0.007 & 0.016 & 0.017 & 0.016 & 0.019 \\
\hline 12 & 0.027 & 0.085 & 0.084 & 0.019 & 0.084 & 0.018 & 0.084 & 0.085 & 0.030 & 0.048 \\
\hline 13 & 0.096 & 0.066 & 0.065 & 0.086 & 0.065 & 0.085 & 0.064 & 0.021 & 0.067 & 0.068 \\
\hline 14 & 0.073 & 0.021 & 0.021 & 0.068 & 0.020 & 0.066 & 0.020 & 0.011 & 0.023 & 0.066 \\
\hline 15 & 0.023 & 0.010 & 0.008 & 0.023 & 0.010 & 0.021 & 0.009 & 0.006 & 0.009 & 0.009 \\
\hline 16 & 0.013 & 0.007 & 0.006 & 0.014 & 0.006 & 0.012 & 0.005 & 0.002 & 0.008 & 0.012 \\
\hline 17 & 0.009 & 0.002 & 0.002 & 0.009 & 0.002 & 0.007 & 0.002 & -0.005 & 0.001 & 0.002 \\
\hline 18 & 0.004 & -0.006 & -0.005 & 0.004 & -0.006 & 0.003 & -0.006 & -0.011 & -0.002 & 0.001 \\
\hline 19 & -0.004 & -0.010 & -0.011 & 0.004 & -0.011 & -0.004 & -0.012 & -0.018 & -0.008 & -0.004 \\
\hline 20 & -0.009 & -0.017 & -0.019 & -0.003 & -0.019 & -0.009 & -0.019 & -0.017 & -0.016 & -0.012 \\
\hline 21 & -0.016 & -0.018 & -0.017 & -0.008 & -0.018 & -0.017 & -0.018 & -0.018 & -0.017 & -0.018 \\
\hline 22 & -0.015 & -0.015 & -0.018 & -0.016 & -0.019 & -0.016 & -0.008 & -0.008 & -0.007 & -0.015 \\
\hline 23 & -0.016 & -0.006 & -0.008 & -0.015 & -0.008 & -0.017 & -0.012 & 0.006 & -0.007 & 0.006 \\
\hline \multicolumn{11}{|c|}{ Average of measured deviations 0.007 [mm] } \\
\hline \multicolumn{11}{|c|}{ Nominal angle value $12.35\left[^{\circ}\right]$} \\
\hline $\begin{array}{l}\text { Angle size } \\
\text { measured }\end{array}$ & 12.336 & 12.297 & 12.296 & 12.297 & 12.339 & 12.296 & 12.340 & 12.297 & 12.347 & 12.336 \\
\hline $\begin{array}{l}\text { Angle } \\
\text { deviation }\end{array}$ & -0.014 & -0.053 & -0.054 & -0.053 & -0.011 & -0.054 & -0.010 & -0.053 & -0.003 & -0.014 \\
\hline
\end{tabular}

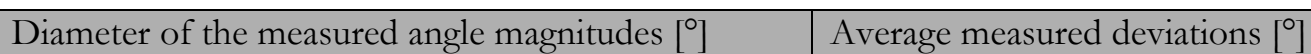


Fig. 4. shows the measurement protocol using the Zeiss 3D system and a table of measured values when checking the Model Test 1 template, see in Tab. 2.

Tab. 2 shows the measured values from the Model 1 Test Control Measurement. The calculated diameter of the measured deviations of the actual shape of the measured template from the ideal shape of the template was $0.007 \mathrm{~mm}$. The calculated diameter of the measured angle magnitudes was $12.318^{\circ}$, when the nominal angle value was $12.35^{\circ}$.

Tab. 3 Measured values Model Test 2

\begin{tabular}{|c|c|c|c|}
\hline \multicolumn{4}{|c|}{ Measurement results Model Test 2} \\
\hline Tracking number & Measured values & Measured deviations & $\begin{array}{c}\text { Circularity devia- } \\
\text { tion }\end{array}$ \\
\hline 1 & 30.554 & 0.054 & 0.118 \\
\hline 2 & 30.555 & 0.055 & 0.119 \\
\hline 3 & 30.554 & 0.054 & 0.119 \\
\hline 4 & 30.554 & 0.054 & 0.118 \\
\hline 5 & 30.550 & 0.050 & 0.118 \\
\hline 6 & 30.551 & 0.051 & 0.117 \\
\hline 7 & 30.551 & 0.051 & 0.118 \\
\hline 8 & 30.555 & 0.055 & 0.118 \\
\hline 9 & 30.554 & 0.054 & 0.119 \\
\hline 10 & 30.550 & 0.050 & 0.118 \\
\hline \multicolumn{3}{|c|}{ Nominal value means [mm] } & \multirow{2}{*}{$\begin{array}{c}\text { Diameter of mea- } \\
\text { sured roundness } \\
\text { variations }[\mathrm{mm}]\end{array}$} \\
\hline \multicolumn{3}{|c|}{30.500} & \\
\hline \multicolumn{3}{|c|}{ Average measured evaluation [mm] } & \multirow{4}{*}{0.118} \\
\hline \multicolumn{3}{|c|}{30.553} & \\
\hline \multicolumn{3}{|c|}{ Average of measured deviations [mm] } & \\
\hline \multicolumn{3}{|c|}{0.053} & \\
\hline
\end{tabular}

For the Model 2 control, the average value of $30.553 \mathrm{~mm}$ diameter was calculated from the measurements. The nominal diameter was $30.500 \mathrm{~mm}$. The
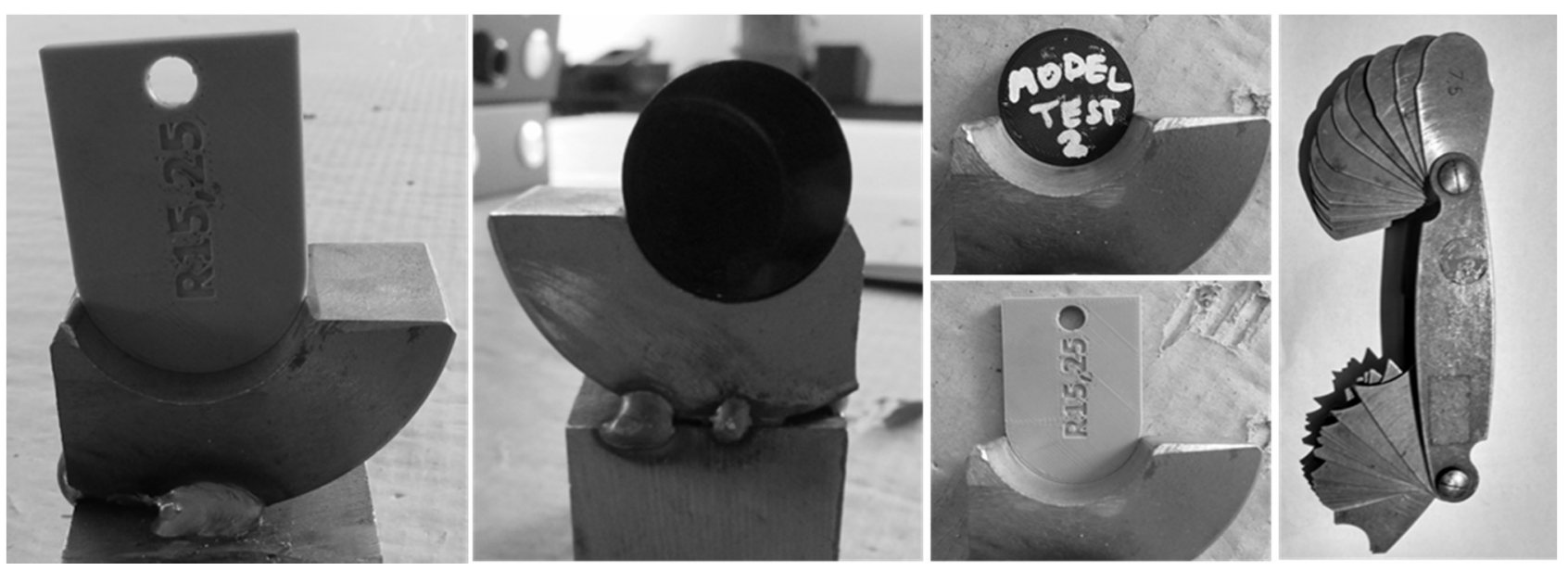

average circularity deviation from the measurements was calculated to be $0.118 \mathrm{~mm}$.

Fig. 5 Check ganges

Final dimensional precision is very important here. In $3 \mathrm{D}$ printing, this is about very precisely adjusting the position of the $\mathrm{X}, \mathrm{Y}$ and $\mathrm{Z}$ axes, positioning them with the use of stepper motors. XYZ Resolution Ultimaker S5 is $6.900 \mu \mathrm{m}, 6.900 \mu \mathrm{m}, 2.500 \mu \mathrm{m}$. Another thing that needs to be taken into consideration is that the material will change its dimensions depending on 
small parts.it can be said that 3D printing technology is very accurate and can be used to print size control templates or to print non-standard radius check gauges as shown in Figure 5.

The third part of the study is devoted to the use of these auxiliary templates in practice, to control dimensions in the production of prototype products.
Figure 6 shows the manufacturing process of the prototype sleeve. The production of the sleeve begins with the development of the sleeve shape (B)from a metal sheet by means of a punching centre (A). Thereafter, the sleeve is successively formed by means of a conventional press brake into a final shape (C).

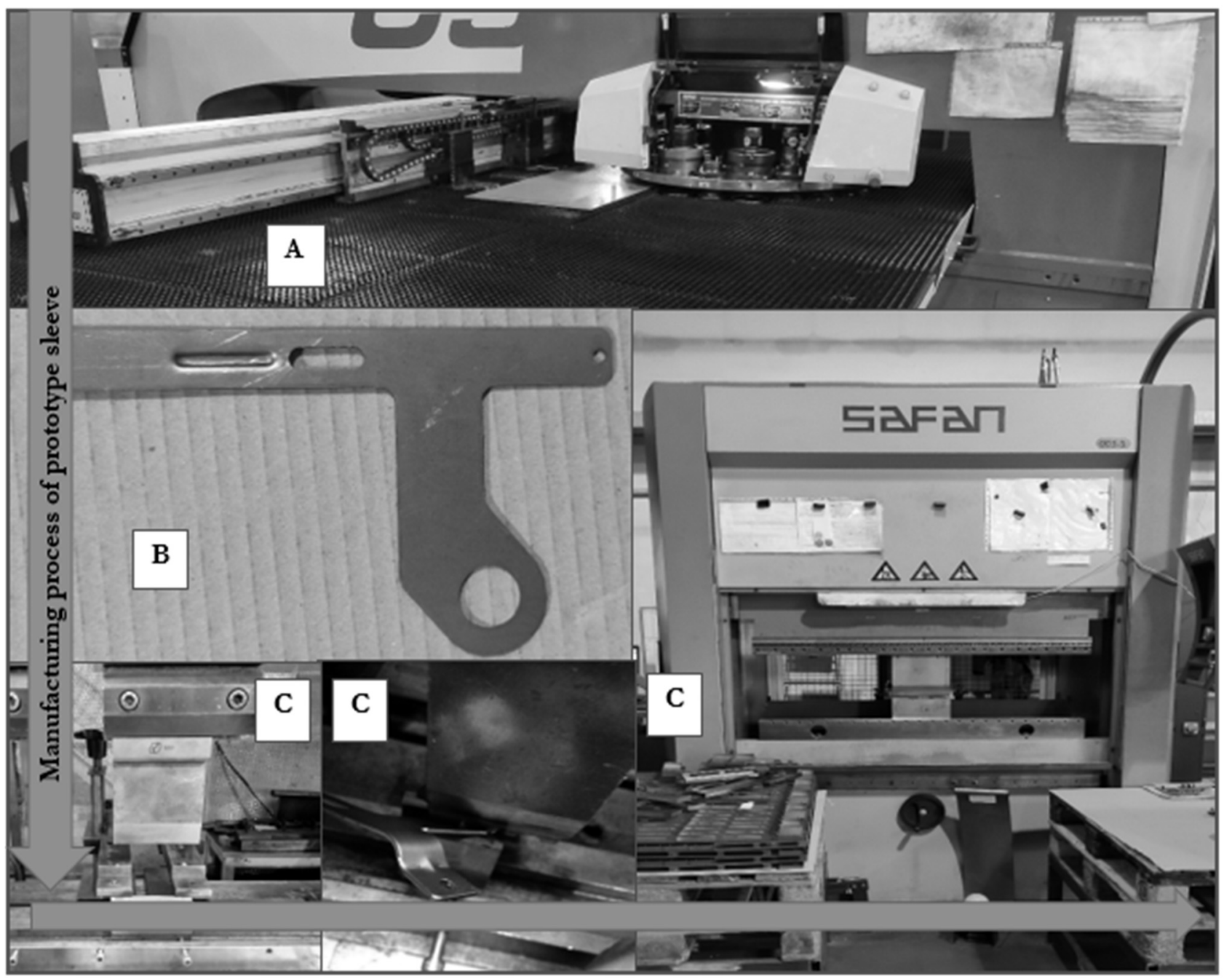

Fig. 6 Manufacturing process of prototype sleeve

3D templates serve as control gauges for complex product shapes. Here, for example, it is the radius or correct bending angle, see in Fig. 7.

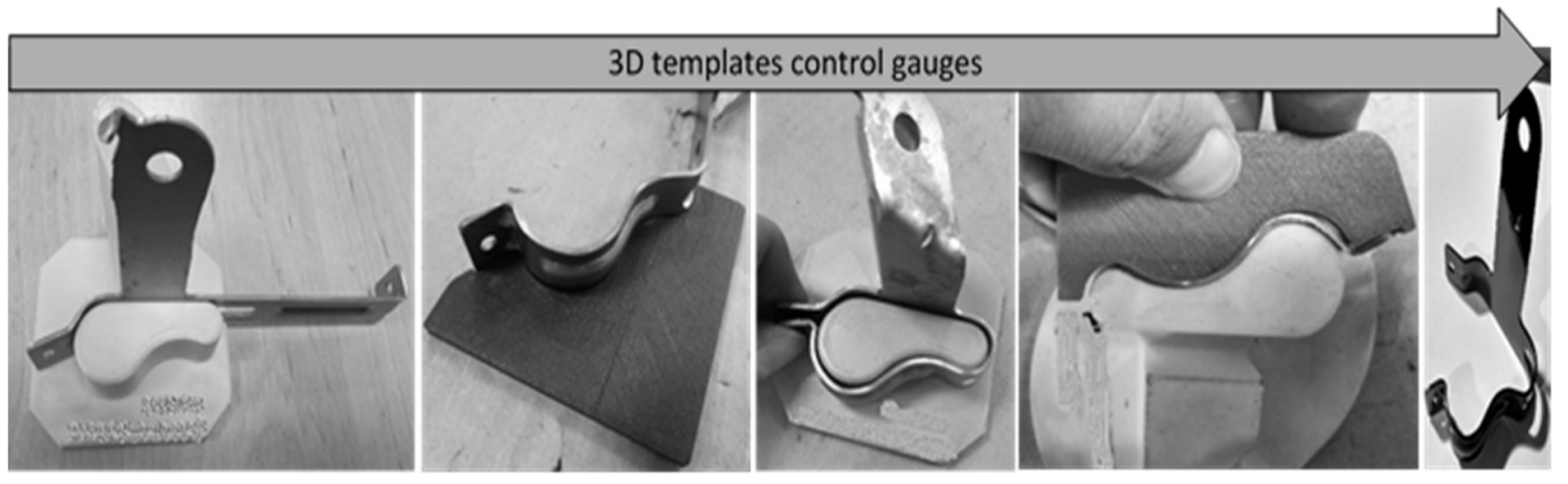

Fig. $73 D$ templates control gauges 
The prototyping itself uses a printed 3D model (product) as a model. This allows us to see the finished product in its actual size and shape, which then helps us technologically plan the sequence of individual bends so that we are able to produce the prototype under the given conditions, see in Fig. 8. Figure 9 shows the computer models of these $3 \mathrm{D}$ templates.

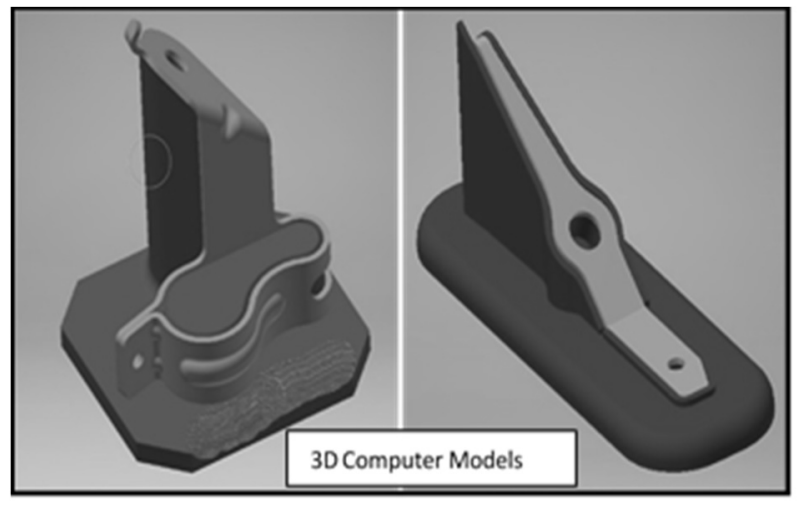

Fig. 8 Computer models 3D templates

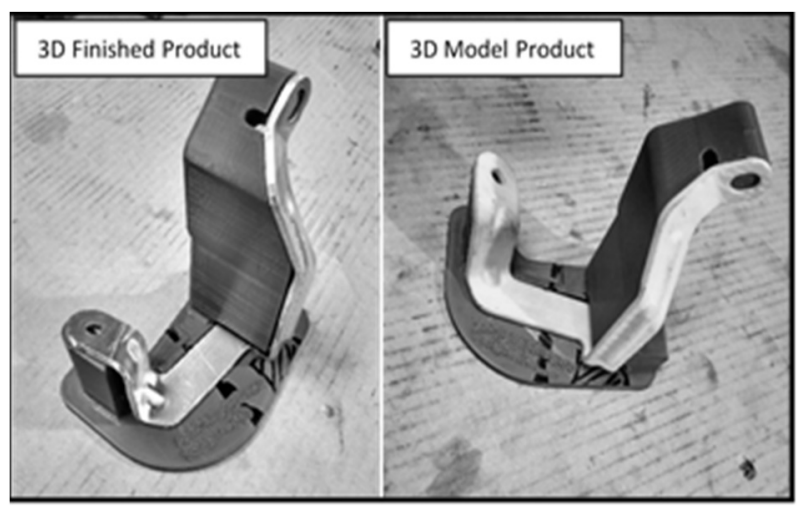

Fig. $93 D$ model (product)

\section{Conclusion}

The case study was focused on 3D printing technology and its use in prototype production. The first part was devoted to the process of 3D template production using 3D printing in real conditions. The second part was focused on checking the accuracy of the produced template using $3 \mathrm{D}$ printing. It has been found that $3 \mathrm{D}$ printing allows us to produce precise shape and size products.

Based on testing model measurement results, and considering both the dimensional precision of a given 3D printer and PLA printing string qualities, it may be concluded that with the given dimension, and keeping the production parameters, very high precision is achieved and the molds can be used as relatively precise gauges.

From the above it is evident that modern 3D printing technology represents the possibility and suitability of integration of modern production technologies in the conditions of single or custom production, which leads to the reduction of costs necessary for the production of prototypes and also the possibility of wider use in practice.

The results of the case study showed the practical use of 3D printing technology in the conditions of engineering prototype production. The combination of conventional sheet metal processing technology and modern 3D printing technology creates unique prototypes without which the physical and mechanical properties of future products could not be tested.

\section{Acknowledgements}

The paper was created with the support of project No. RPP2020/93 (SPP FR3450031).

\section{References}

[1] SCHINDLEROVÁ, V., ŠAJDLEROVÁ, I. (2017) Influence of tool wear on material flow. In. Advances in science and technology research journal, Vol. 11, No. 1, pp.161 - 165. Lublin University of Technology, Poland. ISSN 2299-8624

[2] SHAHRUBUDIN, N., LEE, T.C., RAMLAN, R. (2019). An Overview on 3D Printing Technology: Technological, Materials, and Applications. In: Procedia Manufacturing, Vol. 35, No. 1, pp. 1286 - 1296. ELSEVIER. ISSN: 2351-9789

[3] DANKAR, I., HADDARAH, A., OMAR, F.E.L., SEPULCRE, F., PUJOLA, M. (2018). 3D printing technology: The new era for food customization and elaboration. In: Trends in Food Science \& Technology, Vol. 75, No. 1, pp. 231 -242. ELSEVIER. ISSN: 0924-2244

[4] BIRBARA, N.S., OTTOM, J.M., PATHER, N. (2019). 3D Modelling and Printing Technology to Produce Patient-Specific 3D Models. In: Heart, Lung and Circulation, Vol. 28, No. 2, pp. 302 - 313. ELSEVIER. ISSN: 1443-9506

[5] STRNAD, J., REZNICEK, M., JELINKOVA, K., JANOSTIK, V., OVSIK, M. (2019). Possibilities of Creating a Mechanism on FDM 3D Printer. In: Manufacturing Technology, Vol. 19, No. 3, pp. 508-512. ISSN 1213-2489.

[6] ELMRABET, N., SIEGKAS, P. (2020). Dimensional considerations on the mechanical properties of 3D printed polymer parts. In: Polymer Testing, Vol. 90, Article 106656. ISSN: 0142-9418.

[7] ABEYKOON, CH., SRI-AMPHORN, P., FERNANDO, A. (2020). Optimization of fused deposition modeling parameters for improved PLA and ABS 3D printed structures. In: International Journal of Lightweight Materials and Manufacture, Vol. 3, No. 3, pp. 284-297. ISSN: 2588-8404 
[8] DESHMUKH, K., HOUKAN, M.T., ALMAADEED, M.A., SADASIVUNI, K.K. (2020). 3D and 4D Printing of Polymer Nanocomposite Materials, pp. 1 - 24. ELSEVIER. ISBN: 978-0-12-816805-9

[9] MOHAMMED, J.S. (2016). Applications of $3 \mathrm{D}$ printing technologies in oceanography. In: Methods in Oceanography, Vol. 17, No. 1, pp. 97 117. ELSEVIER. ISSN: 2211-1220

[10] KRIŠTOFOVÁ, P., ROUDNICKÁ, M., KUBÁSEK, J., PALOUŠEK, D., SUCHÝ, J., VOJTĚCH, D. (2019). Influence of Production Parameters on the Properties of 3D Printed Magnesium Alloy Mg-4Y-3RE-Zr (WE43). In: Manufacturing Technology, Vol. 19, No. 4, pp. 613118. ISSN 1213-2489

[11] DUDA, T., RAGHAVAN, L.V. (2016). 3D Metal Printing Technology. In: IF ACPapersOnLine, Vol. 49, No. 29, pp. 103 - 110. ELSEVIER. ISSN: 2405-8963.
[12] VELU, R., RASPALL, F., SINGAMNENI, S. (2019). 3D printing technologies and composite materials for structural applications. Green Composites for Automotive Applications, pp. 171 196. Woodhead Publishing, Singapore. ISBN 978-0-08-102177-4

[13] CHNIEDERJANS, D.G. (2017). Adoption of 3D-printing technologies in manufacturing: A survey analysis. In: International Journal of Production Economics, Vol. 183, No. 1, pp. 287 - 298. ELSEVIER. ISSN: 0925-5273

[14] Ultimaker S5. (2020). Available online: https://ultimaker.com/

[15] PLA Technical Data Sheet. (2020). Available online: https://www.sd3d.com/wpcontent/uploads/2017/06/MaterialTDSPLA_01.pdf 